International Journal of Korean Humanities and Social Sciences

vol. $6 / 2020$

DOI: http://dx.doi.org/10.14746/kr.2020.06.05

\title{
THE REVIEW OF "TRANSLINGUAL WORDS. AN EAST ASIAN LEXICAL ENCOUNTER WITH ENGLISH" BY JIEUN KIAER, 2019. ROUTLEDGE LONDON AND NEW YORK, ISBN: 978-1-351-10947-5, PP. 160
}

by EMILIA WOJTASIK-DZIEKAN, Ph.D.

Institute of Oriental Studies, Faculty of Modern Languages and Literatures, Adam Mickiewicz University, Poznań, Poland
Al. Niepodległości 4, 61-874 Poznań, Poland
emilia.w@amu.edu.pl

ORCID: https://orcid.org/0000-0003-1011-1081

The book, which I decided to review, is another scientific monograph written by Professor Jieun Kiaer from University of Oxford, UK. This book is quite compact and with an interesting approach to the subject of the lexicon, which treats this issue more in terms of penetration of modern functioning than previously common historical-typological approach. It 
is certainly an interesting and future-oriented research aspect for linguistics.

The book consists of three (3) parts, each of which focuses on another aspect of the issues in the analyzed language vocabulary (primarily English - which is indicated in the title; East Asian languages such as Korean, Chinese and Japanese).

The first part is devoted to outlining the very concept of the notion of translingual words introduced by the Author. The Author emphasizes in the introduction (part I) that she is aware of the widespread contemporary linguistic changes that also affect the lexis of a given language, at the same time defining the introduced concept as: "Translingual words are words that live across the borders of languages. These words constantly travel and re-settle in different languages. As a part of their adaptation processes, they gain local forms and meanings." (Kiaer 2019: 1). At the same time, Kiaer indicates a research goal, describing it as the need to change from a monolingual model to a multilingual model, which would allow the accumulation and accumulation of translingual terms in a global lexicon. For this purpose, the use of modern Internet tools (online databases, social media or online varieties of English) is the right approach, allowing the findings to be placed in a broad context.

As already mentioned, the first part is devoted to the issue of the lexicon crossing linguistic borders. This label covers not only the terms of loanwords from Asian languages in English, but also an occurring linguistic correlations (especially lexical) between these languages. It also raises the question of linguistic assimilation deadlines originally borrowed and now no longer treated as foreign because of their dissemination on the Internet. The correlation between languages and their online availability influences not only the increase in the share of loanwords in languages but also their accustoming and the accelerated process of assimilation. Hybrid terms are also no longer a complete novelty, and their presence is becoming more frequent and less and less aware. They are no longer treated as linguistic anomalies that arose by chance - they are words and phrases as important as others. The author even describes it as a linguistic currency: "Hybrid words are not subsidiary or temporary words but are a crucial linguistic currency for those who are constantly exposed to multiple languages." (Kiaer 2019: 22). A separate section is devoted to culturally immersed words, which are distributed among the groups and interests. This affects the individual popularized phrases originally embedded in a particular culture (eg. Kiaer 
gives Korean hallyu, aegyo and Japanese kawaii or Tamagotchi). This is the introduction to section 4, which discusses translingual words based on the lexicon and then transfers it to the global lexicon, examining in the context of form, meaning and origin. Kiaer derives this concept from the idea of translanguaging by García and Wei (2014) and later findings of Otheguy, García, and Reid (2015), pointing out that: "a language provides a communicative environment with a set of phonological and morphosyntactic rules together with specific social conventions." (Kiaer 2019: 42). This part is particularly interesting because of the global approach, pointing at the same time to the process of deriving meaning from the local language to the global language level.

Part II of the book focuses on the history of the emergence of Asian terms in English. The Author places Japanese, Chinese and East Asian terms in general against the background of historical, political, trade and cultural contacts. Kiaer pays special attention to terms of Chinese origin, at the same time emphasizing their transformation process in a linguistic assimilation into Korean or Japanese, and at the same time perceiving them in English as being of Chinese origin. By analyzing words and phrases related to culinary, philosophy or regions, Kiaer also tries to outline the direction of the individual words geopolitical transfer to finally reach the stage of lexical linguistic variations due to electronic and printed media use, and the degree of word integration into English. This part is accompanied by a three case analysis of Asian terms in press texts written in English, making the author's argument credible. The problematic issue of the East Asian terms romanization in English is also noteworthy.

Part three (III) - the last one - is also devoted to terms of foreign origin, but in the opposite direction than in the first two parts of the book - it discusses the issue of English terms in aforementioned East Asian languages. The historical background of introducing English terms into Japanese, Chinese and Korean is analyzed as the most common methods of English lexicon transfer by translation or transliteration. In addition to history in brief, some present conditions are also indicated, especially these related to technological development and progress, as well as motivation to incorporate terms related to the users attitude.

The depiction of the formal language approach of the various institutions in China, Japan, Korea and Taiwan to the terms of English origin is particularly interesting. This subsection is an introduction and a logical bracket with the next subsection (9), dealing with the problem of creating English words through the prism of the leading Asian language. 
Kiaer refers to the creating lexis functioning rules by compounding, shortening, clipping, derivation and blending of local and English words, devoting some attention to morphemes related to internet vocabulary (web-; -net), also discussing the linguistic phenomenon of Chinese-born English words (WeChat; Weibo) and word-formation shifts of English terms with a semantic shift in Korean.

The last chapter focuses on the semantics of selected categories of words related to fashion and cosmetics, society and culture, food and foreign brands, emphasizing not only frequent semantic shifts but also word-formation tendencies, especially in the field of technology (prefix $e^{-}$, eco-, words smart or cyber) .

The book is written substantively and discusses quite complicated word-formation issues in relation to English and Korean, Chinese or Japanese languages in a pleasantly accessible way. Mostly modern vocabulary was used as a research material reflecting the researcher's approach to demonstrating the linguistical transgression of borders. From the structural point of view, the book is also well-written and the individual chapters and parts connect very well, binding the introduced issues. I believe this is a monograph that every Koreanist, and in a broader context also an orientalist researcher working on the relationship between East Asian languages and English, should take a closer look at.

\section{References}

Kiaer, Jieun. 2019. Translingual Words. An East Asian Lexical Encounter with English. Routledge: London and New York.

García, Ofelia and Wei, Li. 2014. Translanguaging: Language, Bilingualism and Education. Palgrave Pivot: Basingstoke.

Otheguy, Ricardo, García, Ofelia and Reid, Wallis. 2015. Clarifying translanguaging and deconstructing named languages: A perspective from linguistics. Applied Linguistics Review 6(3): 281-307. 